\title{
AN UNUSUAL LEAD POINT IN AN UNUSUAL INTUSSUSCEPTION-A CASE REPORT
}

KEY WORDS:

Intussusception,small bowel obstruction,feeding gastrostomy,lead point,vomiting
Dr.Suganth.....*

Dr.Padmanabhan .S.R

\section{Dr.Kannan.R}

Post graduate ,Institute of General surgery ,Madras Medical college and Rajiv Gandhi Government General Hospital, Chennai-3. *Corresponding Author

Assistant professor,Institute of General surgery ,Madras Medical college and Rajiv Gandhi Government General Hospital,Chennai-3.

Director, Institute of General surgery ,Madras Medical college and Rajiv Gandhi Government General Hospital, Chennai-3.

Intussusception is one of the causes of small bowel obstruction. This is a case report of 48years old female patient who came to casualty with complaints of abdomen distension for 3days and abdomen pain for 2days associated with vomiting and constipation.History of surgery done for feeding gastrostomy tube placement done $6 \mathrm{months}$ ago .On examination abdomen distended and CECT abdomen report showing small bowel intussusception.Emergency Laparotomy done and jejuno-jejunal intussusception seen with bulb of feeding gastrostomy tube as lead point.Bowel found to be viable and invaginated bowel reduced. Feeding tube migration should be suspected in patients with feeding tubes presenting as small bowel obstruction.

\section{INTRODUCTION}

- Intussusception occurs when one portion of bowel invaginates into an immediately adjacent segment of bowel causing intestinal obstruction.

- Most common in children with peak incidence between 5 months and 10months of age.About $90 \%$ of cases are idiopathic.

- After the age of 2years a pathological lead point is found in at at least one third of children

- Adult cases are invariably associated with a lead point which is usually a polyp,submucosal lipoma or tumour.

\section{Case report:}

- 48years old female patient came to casualty with complaints of abdomen distension for 3days and abdomen pain for 2 days

- History of presenting illness:6months back Patient has been diagnosed with hypopharynx carcinoma for which chemotherapy and radiotherapy given.

- Tracheostomy and feeding gastrostomy done 6months back.

- Patient complained of abdomen distension on and off for 2months after feeding through gastrotomy tube.

- Abdomen distension increased on feeding through gastrostomy and decreased when feeding is stopped.

- Now patient complained of abdomen pain with distension for 3days not relieved even after stopping feeding.

- History of 2episodes of vomiting

- History of constipation+

- No history of obstipation/melena/bleeding per rectum

- No history of jaundice/fever/loose stools

- No history of breathlessness /decreased urine output

- Menstrual and marital history:

- Married and has ldaughter.Attained menopause lyear back.

\section{General examination:}

Patient thin built, conscious, oriented, afebrile

No pallor/icterus/clubbing/Lympadenopathy/pedal edema

Vitals-bp:120/70mm ng. Pulse rate:96/min

\section{Systemic examination:}

Cvs:sls2+ no murmurs heard

RS:bilateral normal vesicular breath sounds heard

\section{Abdomen:}

Inspection:Abdomen distended,upper midline scar seen.Feeding gastrostomy tube seen not anchored to abdomen wall
No vgp/VIP/dilated veins /sinuses. Hernial orifices free

- Palpation:Abdomen soft, distended,tenderness present in Peri umbilical region

no guarding/no rigidity

Percussion: no free fluid

Auscultation:Bowel sounds sluggish

PR:empty no fecal staining

\section{PV:Fornices Free}

- Xray abdomen erect showed no air under diaphragm and stomach was dilated.

CECT abdomen showed target sign with possibility of jejunojejunal intussusception.

\section{PICTURE 1:CECT ABDOIMEN SHOWING TARGET SIGN}

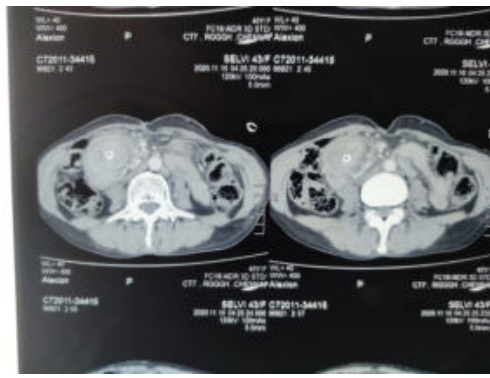

- Patient was shifted to theater for laparatomy.

- Findings were:distal segment of jejunum found invaginating into another segment of jejunum with the lead point being inflated bulb of gastrostomy tube.

- Stomach and proximal jejunum found to be dilated.

- No free fluid in abdomen.

- Other abdomen viscera found to be Normal.

\section{Proceedings:}

Proceeded with milking of jejunal segment which was invaginated into adjacent jejunum.

Feeding gastrostomy tube had migrated from stomach into proximal jejunum with inflated bulb which was the lead point .

- Both segments of jejunum found to be edematous but peristalsis present.

- Feeding gastrostomy tube deflated and pushed back into stomach and fixed with 2-0 silk. 
- Abdomen closed in layers

\section{PICTURE 2:Jejuno-jejunal intussusception -retrograde}

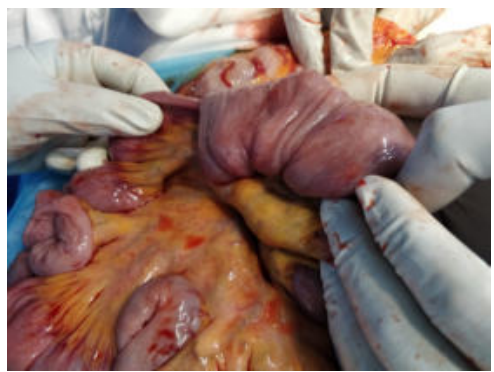

\section{DISCUSSION}

- Intussusception is most common in children

- In adults intussusception accounts for $2 \%$ of bowel obstruction in adults

- In adults the median age of presentation is sixth to seventh decade.

- Adult cases are secondary to intestinal pathology eg:polyp,meckel's diverticulum.

- Neoplasms causing intussusception are malignant in 50\% of cases

\section{Pathology:}

- An intussusception is composed of 3parts namely

- Entering tube/inner tube/intussusceptum

- Returning tube/middle tube

- Sheath/outer tube/intussuscipiens

- Apex:The part that advances

Neck:junction of the entering layer with mass

\section{TYPES OF INTUSSUSCEPTION:}

- Ileocolic-most common in children

- Ileoileal

- Ileoileocolic

- Colocolic-most common in adults.

- Multiple

- Retrograde

- The degree of ischemia depends on the tightness of invagination

- Complications that arise from gastroenteral feeding tubes include tube migration/perforation/Blockage or leakage Rarely the feeding tubes cause proximal small bowel intussusception

\section{THEORIES THAT EXPLAIN THE MECHANISIM OF} FEEDING TUBES CAUSING INTUSSUSCEPTION:

- The tip of the feeding tube can act as leading point and can drag the proximal segment of bowel into distal during a peristaltic wave

- Retrograde peristalsis of jejunum during vomiting

- The injecting force from the pump during feeding can also drag the bowel

- An increased length of the feeding tube can cause distal tip migration

On examination, abdomen initially not distended.

- Sausage shaped lump with concavity towards umbilicus is felt in $60 \%$ cases

- Sign of dance:feeling of emptiness in right Iliac fossa

- $\quad$ PR :blood stained mucous may be found on finger

\section{Investigations:}

- Xray abdomen erect-absence of caecal gas shadow in ileocolic cases

- Bariium enema-claw sign in ileocolic intussusception

- Ultrasound abdomen and pelvis-Sensitive in children. Doughnut appearance Of concencentric rings on transverse section

- CECT abdomen-most sensitive 58-100\%sensitive.Target or sausage shaped
Soft tissue mass with a layering effect.

\section{Treatment:}

- In children radiological reduction is tried .Air or barium enema tried.

- Non operative reduction contraindicated if there is signs of peritonitis/perforation or presence of pathological lead point or if patient is in shock

- Strangulated bowel and pathological lead points are unlikely to reduce

- Recurrent intussusception occurs in $10 \%$ of cases after non operative reduction

- Adults require surgery.

- Reduction is achieved by gently compressing the most distal part of intussusception towards origin making sure not to pull.

- After reduction the viability of bowel is checked carefully.

If it is irreducible/infarcted/pathological lead point-resection with primary anastomosis

\section{CONCLUSION:}

- In a patient with small bowel obstruction with history of feeding tubes placement ,intussusception should be in mind.

- Risk of intussusception increases with increasing calibre /longer length of feeding tubes.Tip migration can be prevented by fixation of feeding gastrostomy tube with skin .

- Removal of feeding tubes not necessary to prevent recurrence

\section{REFERENCES:}

1. Dholaria, S., Lakhera, K.K. \& Patni, S. Intussusception: a Rare Complication After Feeding Jejunostomy; a Case Report. Indian J Surg Oncol 8, 188-190 (2017).https://doi.org/10.1007/s13193-016-0604-3

2. Archimandritis AJ, Hatzopoulos N, Hatzinikolaou P, Sougioultzis S, Kourtesas D, Papastratis G, Tzivras M. Jejunogastric intussusception presented with hematemesis: a case presentation and review of the literature. BMC Gastroenterol. 2001;1:1. doi: 10.1186/1471-230x-1-1. Epub 2001 Jan 4. PMID: 11178112;PMCID:PMC29076.

3. Marinis A,Yiallourou A, Samanides L, Dafnios N, Anastasopoulos G,Vassiliou I, Theodosopoulos T. Intussusception of the bowel in adults: A review. World J Gastroenterol 2009; 15(4):407-411

4. Hughes UM, Connolly BL, Chait PG, Muraca S. Further report of small-bowel intussusceptions related to gastrojejunostomy tubes. Pediatr Radiol. 2000 Sep;30(9):614-7.doi:10.1007/s002470000260.PMID: 11009299 